\title{
Airway responsiveness in low birthweight children and their mothers
}

\author{
K N CHAN, C M NOBLE-JAMIESON, A ELLIMAN, $\dagger$ E M BRYAN, $\uparrow$ V R ABER, ${ }^{*}$ \\ AND M SILVERMAN
}

Paediatric Department and ${ }^{*}$ Computer Centre, Royal Postgraduate Medical School, Hammersmith Hospital, and †Paediatric Department, Queen Charlotte's Maternity Hospital, London

SUMMARY In a prospective study on a cohort of 7 year old children of low birth weight (under $2000 \mathrm{~g}$ at birth), we observed an increased prevalence of airway responsiveness to histamine compared with a reference population of unselected, local schoolchildren. The airway responsiveness to histamine was significantly related to a history of asthma in first degree relatives (natural parents and siblings) in both groups of children, but not to that of the mothers. There was no increase in the prevalence of maternal asthma, a family history of asthma, or airway responsiveness in the mothers of low birthweight children. We were unable to find evidence to support the hypothesis that maternal smooth muscle irritability (uterine and airway) has a causative role in the premature labour in the mothers and in subsequent bronchial hyperresponsiveness in their prematurely born children.

Increased airway responsiveness to histamine or methacholine has been reported in long term survivors of bronchopulmonary dysplasia ${ }^{1}$ and respiratory distress syndrome,$^{2}$ and after neonatal mechanical ventilation, ${ }^{4}$ suggesting that neonatal respiratory illness and its treatment are associated with airway hyper-responsiveness detectable many years later. The importance of such observations is immense as they could imply a much worse prognosis for adult obstructive airway disease than might formerly have been suspected.

Recently bronchial hyper-responsiveness has also been shown in prematurely born children without neonatal respiratory illness. ${ }^{35}$ Bertrand et al have even shown that both the full term siblings and mothers of preterm children have a much greater level of airway responsiveness than control groups. ${ }^{3}$ While their study was small and could have suffered from bias, their hypothesis was ingenious: irritability of both uterine and airway smooth muscle of the mothers could act as a common pathway in the aetiology both of premature labour and of bronchial hyper-responsiveness in both mothers and their children (full term and preterm). This hypothesis is supported by the use of selective $\beta$ adrenergic agents to reduce uterine smooth muscle activity in obstetrics and smooth muscle activity in airway disease. Further supporting evidence comes from the observation that a family history of asthma, of which increased airway responsiveness is an associated manifestation, is commoner in survivors of bronchopulmonary dysplasia ${ }^{6}$ and respiratory distress syndrome. ${ }^{3}$ The hypothesis of Bertrand et al has not been adequately tested.

The reports published so far are all retrospective studies based on small samples of hospital populations, often without adequate control groups. They suffer from potentially severe sampling bias, such that the inferences that can be deduced are limited by their study design. The true prevalence of airway responsiveness in populations of preterm, low birthweight children is not known.

In this paper we report the initial results of lung function tests from a prospective study of a cohort of low birthweight children and a random reference population of schoolchildren of the same age. 'The study aimed to determine the distribution of airway responsiveness to histamine, the relation between airway responsiveness and maternal or family history of asthma, and the prevalence of airway hyperresponsiveness in mothers of low birthweight children.

\section{Subjects and methods}

All infants of birth weight between 500 and $2000 \mathrm{~g}$ 
born in the 12 month period from June 1979 to May 1980, at Hammersmith and Queen Charlotte's Hospitals, were recruited into a long term multidisciplinary follow up study from birth. Perinatal data were recorded soon after discharge from the neonatal unit. Of the 218 survivors in this cohort of 294 live births, one refused to take part in this study, 23 were known to have emigrated, and three were lost to follow up. At 7 years of age (mean (SD) age 7.00 $(0 \cdot 16)$, range $6 \cdot 2-7 \cdot 9$ years) 134 children attended the lung function clinic. Of the 57 who did not have lung function tests, 38 lived at a distance (outside the boundaries of Greater London), three had severe mental retardation, and one was in care with the social services department. Comprehensive information was also available on seven members of multiple births whose birth weight was over $2000 \mathrm{~g}$. Although not included in the cohort, they were documented in the same way as their low birthweight twin or triplet.

In the second half of our study, all mothers who accompanied their children to our clinic were invited to take part in the histamine challenge test. Out of 37 requests, 36 consented to take part. One mother who was unable to perform reproducible peak flow manoeuvres due to muscle disease did not take part. Thirty five mothers completed the airway response test to histamine.

We also carried out lung function tests and airway response tests to histamine in a reference population of schoolchildren recruited from three schools near to Hammersmith Hospital. All 166 pupils in the third and fourth years whose age was between 6 and 8 years at the time of the school visits were included. Parental consent was sought by sending parents of each child an explanatory letter together with a questionnaire through the class teachers. Twenty two parents did not reply and 16 parents did not give consent. Of the 128 parental consents obtained ( $77 \%$ of the total), two arrived after the whole study had been completed. Three children were absent from school due to illness after having obtained parental consent and three children were not tested because they had active colds. Four children did not consent to the test and the test was discontinued in a further four because of hoarseness and coughing. The airway response test was completed by 112 children in the reference group. Their mean (SD) age was $6.95(0.43)$ years (range $6.2-8.0$ years).

An identical questionnaire was used to determine the personal and family history of members of the low birthweight cohort and the reference children. The following features of relevance to this study were recorded: personal history of cough and wheeze, asthma or atopic illness; and history of asthma or other atopic illness in parents and siblings. Ques- tionnaires were sometimes incompletely filled and this is reflected in the varying numbers which are reported in the tables.

The tests on low birthweight children were carried out at hospital clinics over the course of one year, whereas the control population of schoolchildren was studied over a period of six weeks in February and March 1987 at their schools.

We used the rapid method developed by Yan et al to measure airway responsiveness, ${ }^{7}$ using handheld DeVilbiss No 40 nebulisers. The histamine solutions at different concentrations were prepared at weekly intervals by serial dilution with saline from a stock solution of $32 \mathrm{mg} / \mathrm{ml}$ unbuffered histamine acid phosphate prepared by the pharmacy at Hammersmith Hospital. The histamine solutions used for airway provocation tests were all freshly drawn from these solutions at the beginning of each session. The output of these nebulisers had been assessed and checked before tests were carried out. Peak expiratory flow rate as recorded by the Wright peak flow meter (Airmed) was used to measure changes in airway function.

After being adequately taught the peak flow technique, the children were asked to perform four peak flow manoeuvres to establish within subject reproducibility of peak expiratory flow rate before any aerosol was given. After nebulised saline administration to exclude a non-specific airway response to aerosol, the children were given doubling doses of histamine according to the schedule shown in table 1 . Sixty seconds after each administration, two recordings of peak expiratory flow rate were obtained, followed immediately by the next dose of histamine. If the difference between the two recordings was greater than $10 \%$, a third attempt was requested. The highest value was used in analysis. Increasing doses of histamine were given according to schedule until the fall in peak expiratory flow rate exceeded $20 \%$ from the baseline post-saline level or until a maximum cumulative dose of $6 \mu \mathrm{mol}$ had

Table 1 Histamine dose schedule

\begin{tabular}{llll}
\hline $\begin{array}{l}\text { Dose } \\
\text { number }\end{array}$ & $\begin{array}{l}\text { Histamine } \\
\text { solution } \\
\text { concentration } \\
(m g / m l)\end{array}$ & $\begin{array}{l}\text { No of } \\
\text { puffs }\end{array}$ & $\begin{array}{l}\text { Cumulative } \\
\text { dose }(\mu \mathrm{mol})\end{array}$ \\
\hline 1 & 2 & 2 & \\
2 & 2 & 4 & 0.07 \\
3 & 8 & 2 & $0 \cdot 15$ \\
4 & 8 & 4 & 0.33 \\
5 & 32 & 2 & 0.7 \\
6 & 32 & 4 & $1 \cdot 5$ \\
7 & 32 & 8 & 3.0 \\
\hline
\end{tabular}


been given, whichever was the sooner. The children were seated throughout the test.

A dose response curve was constructed by plotting the highest peak expiratory flow rate against the cumulative dose of histamine on a log scale. The cumulative dose of histamine required to cause $20 \%$ fall in peak expiratory flow rate from the post-saline level $\left(\mathrm{PD}_{20}\right)$ was obtained by linear interpolation of the dose-response curve.

During the course of the study, when it became apparent that there were no children with a $\mathrm{PD}_{20}$ less than the second dose of histamine in our schedule, the protocol was modified by combining the first and second doses as one single dose (4 $\mathrm{mg} / \mathrm{ml}$, three puffs).

The same method was used to measure airway responsiveness in the mothers of low birthweight children and in the reference population of healthy schoolchildren.

Skin prick tests for atopy were carried out in the low birthweight children but not in the control population. Three common allergens-namely, housedust mite, group B grass pollens, and cat fur (Bencard) - were administered together with a control solution. A skin test was considered to be positive if there was a weal of $2 \mathrm{~mm}$ or more in diameter to any one of the allergens in the absence of any response to the control solution.

Neonatal history and questionnaires were not analysed until the whole of the study had been completed. The neonatal history of the children was not known at the time of testing.

Statistical analysis of the distributions of airway responsiveness in the two populations of children was done by Mann-Whitney U test. Significance of the association between various factors and the presence of airway responsiveness, and the comparison of the prevalence of these factors in the two populations of children was assessed by the $\chi^{2}$ test.

Written consent was obtained from the parents of all subjects. The studies were approved by local ethics committees.

\section{Results}

Of the 134 children from the low birthweight cohort who attended our clinic, 122 completed the airway response test satisfactorily. Three children were unable to take part in breathing tests at all because of the presence of tracheostomy in one and mental retardation in the other two. A further two were unable to perform reproducible peak flows due to coordination difficulties relating to underlying neurological problems. Two children were unable to produce a peak flow greater than $80 \mathrm{1} /$ minute and one child who had a cold did not take part in the test. Four children refused the airway response test.
The mean (SD) birth weight of the 122 children who completed the airway response test in the cohort was 1472 (348) g (range 730-1990 g), and the mean (SD) gestational age was $31 \cdot 8(2 \cdot 8)$ weeks (range 27-39 weeks). Eight children were of gestational age 37 weeks or over, but were small for gestational age. Altogether there were 45 small for dates babies (birth weight under 10th centile for gestational age). On the basis of questionnaire reports from parents of the reference schoolchildren there were three preterm children of gestational age between 35 and 36 weeks. None weighed below $2000 \mathrm{~g}$ at birth.

A total of $87(71 \%)$ of the low birthweight children had a $\mathrm{PD}_{20}$ of $6 \mu \mathrm{mol}$ or less compared with $48(43 \%)$ children in the control population (table 2 ). The frequency distribution of the airway response to histamine in both populations was continuous, with that for the low birthweight children significantly shifted to the left compared with the controls (figure). The median for the low birthweight children was around $4 \mu \mathrm{mol}$ whereas that for

Table 2 Airway responsiveness to histamine

\begin{tabular}{lllll}
\hline Cohort & $P D_{20}{ }^{*}(\mu \mathrm{mol})$ & & \\
\cline { 2 - 5 } & $\begin{array}{l}0-1 \\
\text { No }(\%)\end{array}$ & $\begin{array}{l}>1-3 \\
\text { No }(\%)\end{array}$ & $\begin{array}{l}>3-6 \\
\text { No }(\%)\end{array}$ & $\begin{array}{l}>6 \\
\text { No }(\%)\end{array}$ \\
\hline $\begin{array}{c}\text { Low birth weight } \\
(\mathrm{n}=122)\end{array}$ & $18(15)$ & $35(28 \cdot 5)$ & $34(28)$ & $35(28 \cdot 5)$ \\
$\begin{array}{c}\text { Reference } \\
(\mathrm{n}=112)\end{array}$ & $10(9)$ & $19(17)$ & $19(17)$ & $64(57)$ \\
\hline
\end{tabular}

$\chi^{2}=18 \cdot 2 ; \mathrm{p}<0 \cdot 001$.

${ }^{*} \mathrm{PD}_{20}$ is the cumulative dose of histamine required to cause $20 \%$ fall in peak expiratory flow rate from the post-saline level.

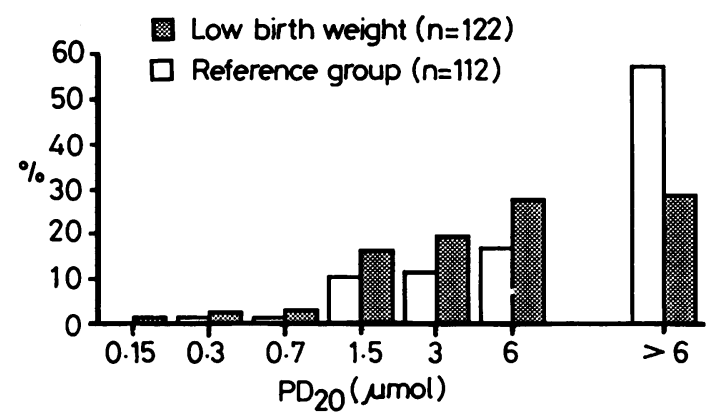

Figure Frequency distribution of airway responsiveness to histamine in 7 year old low birthweight children and a reference population. The cumulative dose of histamine required to cause $20 \%$ fall in peak expiratory flow rate from the post-saline level $\left(P D_{20}\right)$ is plotted on a $\log _{10}$ scale. 
the reference populations was greater than $6 \mu \mathrm{mol}$ (Mann Whitney U test $p<0.001$ ).

Using the same protocol, five of the 35 mothers of low birthweight children (14\%) showed a positive airway response to histamine to a maximum cumulative dose of up to $6 \mu \mathrm{mol}$. The results of a survey of airway responsiveness to histamine in an adult population carried out by Woolcock $e t$ al, using the same technique but with a lower maximum cumulative dose of $3.9 \mu \mathrm{mol}$, reported a prevalence of $10.5 \%{ }^{8}$ At a dose of $3.9 \mu \mathrm{mol}$ the prevalence of airway responsiveness in the mothers of our low birthweight cohort was almost identical at $8 \cdot 6 \%$.

There was no significant difference in the prevalence of asthma in the subjects, their mothers, or first degree relatives, between the low birthweight and reference populations of children (table 3 ). There was a significant association between a personal or a family history of asthma (but not of maternal asthma alone) and increased airway responsiveness in both the low birthweight and reference children (tables 4 and 5). There was also a significant association between positive skin test to common allergens and airway hyper-responsiveness in the low birthweight children $\left(\chi^{2}=7.9 ; p<0.005\right)$. Within the low birthweight cohort, the six mothers with asthma did not go more frequently into spontaneous preterm labour than the non-asthmatic mothers.

Table 3 Prevalence of asthma in study subjects and members of close family*

\begin{tabular}{llllr}
\hline Cohort & $\begin{array}{l}\text { Subjects } \\
\text { No (total) }\end{array}$ & $\begin{array}{l}\text { Fathers } \\
\text { No (total) }\end{array}$ & $\begin{array}{l}\text { Mothers } \\
\text { No (total) }\end{array}$ & $\begin{array}{l}\text { Siblings } \\
\text { No (total) }\end{array}$ \\
\hline Low birth weight & $13(122)$ & $6(120)$ & $6(120)$ & $11(99)$ \\
Reference & $13(105)$ & $5(99)$ & $8(110)$ & $8(90)$ \\
\hline
\end{tabular}

*Variation in numbers in brackets is due to the presence of multiple births, brothers and sisters at the same school, single parent families, missing data due to unknown state of natural parents, and incompletely filled questionnaires.

Table 4 Relation between personal history of asthma and airway responsiveness to histamine

\begin{tabular}{lllllll}
\hline Cohort & $\begin{array}{l}\text { Personal } \\
\text { history }\end{array}$ & \multicolumn{2}{c}{$P D_{20}{ }^{*}(\mu \mathrm{mol})$} & $\chi^{2}$ & $p$ Value \\
\cline { 2 - 5 } & $\begin{array}{l}\text { of } \\
\text { asthma }\end{array}$ & $0-3$ & $>3$ & & \\
\hline Low birth weight & Yes & 10 & 1 & $11 \cdot 1$ & $<0.001$ \\
$(\mathrm{n}=122)$ & No & 43 & 68 & & \\
$\begin{array}{l}\text { Reference } \\
(\mathrm{n}=105)\end{array}$ & Yes & 7 & 5 & 8.9 & $<0.005$ \\
& No & 18 & 75 & & \\
\hline
\end{tabular}

${ }^{*} \mathrm{PD}_{2 n}$ is the cumulative dose of histamine required to cause $20 \%$ fall in peak expiratory flow rate from the post-saline level.
Table 5 Relation between family history of asthma* and airway responsiveness to histamine

\begin{tabular}{lllllll}
\hline Cohort & $\begin{array}{l}\text { Family } \\
\text { history } \\
\text { of }\end{array}$ & \multicolumn{2}{l}{$P D_{20} \dagger(\mu \mathrm{mol})$} & $\chi^{2}$ & $p$ Value \\
\cline { 3 - 5 } & asthma & $0-3$ & $>3$ & & \\
\hline & Yes & 12 & 6 & 4.5 & $<0.05$ \\
$\begin{array}{l}\text { Low birth weight } \\
(\mathrm{n}=121)\end{array}$ & No & 41 & 62 & & \\
$\begin{array}{l}\text { Reference } \\
(\mathrm{n}=99)\end{array}$ & Yes & 9 & 9 & 6.4 & $<0.025$ \\
\hline
\end{tabular}

${ }^{*}$ In natural parents and siblings.

$+\mathrm{PD}_{20}$ is the cumulative dose of histamine required to cause $20 \%$ fall in peak expiratory flow rate from the post-saline level.

\section{Discussion}

As a result of other selective, retrospective studies, it has been stated that asthma may contribute to the chronic lung disease which sometimes follows intensive care of preterm infants. ${ }^{6}$ There are several ways in which an association between asthma and chronic lung disease could come about. A causal relation would be the simplest. Bertrand et al provided evidence for an alternative hypothesis by showing that the mothers of preterm infants in general had hyper-responsive airways. ${ }^{3}$ They proposed that prematurity and later airway abnormalities were linked by familial smooth muscle hyper-responsiveness: uterine and airway smooth muscle in mothers and airway smooth muscle in their children. In order to confirm their hypothesis, it is essential to show that:

(1) the prevalence of airway responsiveness in low birthweight children is increased compared with a reference population of equivalent age; (2) the prevalance of airways responsiveness in the mothers of these children is higher than that of the general adult population;

(3) a maternal history of asthma is commoner in the low birthweight children; and

(4) airway responsiveness in these children is particularly related to the maternal history of asthma.

In our study we showed that the prevalence of airway responsiveness was increased in the low birthweight population $(71 \%)$ compared with that of the reference group (43\%). This observation was in accordance with that reported by Bertrand et al (77\% of the premature children showed a positive response to histamine) $)^{3}$ and MacLusky et al (65\% showed a positive response to methacholine). ${ }^{5} \mathrm{We}$ were, however, unable to show that the prevalence of airway responsiveness in mothers of low birthweight children was greater that that of the general adult population as reported by Woolcock et al using 
the same methodology. ${ }^{8}$ On the basis of self administered questionnaires completed by the children's parents, there was no difference between the low birthweight cohort and the reference group in the prevalence of asthma among mothers or other family members (table 3 ). Finally, we showed that airway responsiveness in children was related to a personal and a family history of asthma in general and not particularly to a maternal history of asthma (tables 4 and 5).

In this prospectively studied cohort of low birthweight children, we found no evidence to support any association between premature labour and maternal airway hyper-responsiveness (and by implication, uterine smooth muscle responsiveness). Moreover, although a family history of asthma was more common in children with increased airway responsiveness, suggesting a familial component in airway responsiveness, this applied to both low birthweight children and to the reference group. The differences between our study and previous observations require explanation.

There are inherent dangers in extrapolating results from limited retrospective studies. ${ }^{36}$ Observations based on small hospital based samples suffer not only from selection bias, but also bias due to willingness of the solicited subjects and their control group to take part in research studies. Consequently the study sample could be biased towards those who had closer hospital or clinic connections or those with more frequent symptoms. Our study cohort was unbiased, age and birthweight specific, and recruited in the neonatal period.

As in any longitudinal study entailing long periods between the time of inception and the time of observation, some loss of follow up is inevitable. Of the original cohort of 218 survivors, we saw $67 \%$ of all available survivors in the United Kingdom in our lung function clinic. Of those who did not come to our clinic, $66 \%$ lived outside the boundaries of Greater London. There was no significant difference in mean birth weight and gestational age between those who attended lung function clinics and completed the tests (1472 $\mathrm{g}$ and 31.8 weeks) and those who did not (1535 g and 31.7 weeks). We nevertheless sent the parents of these children questionnaires identical to those used in our study. Of the 25 replies received out of a total of 57 sent, there was no significant difference in the prevalence of respiratory symptoms or asthma in their families. Their omission is unlikely to have affected our results or conclusions.

It is impossible to find out the airway responsiveness in those low birthweight children who died as infants. We cannot say whether their deaths could have been in any way related to their endogenous airway responsiveness. On the basis of the questionnaire administered to mothers in the neonatal period, neonatal and postneonatal deaths were not associated with an increased prevalence of maternal history of asthma and hay fever.

Airway hyper-responsiveness to chemical irritants such as histamine and methacholine is an established feature of childhood asthma. ${ }^{9}$ Its presence has been shown to be significantly related to respiratory symptoms based on a conglomeration of positive responses to questions about wheeze, exercise wheeze, and night cough. ${ }^{10}$ It has also been observed in children with a variety of chronic airway diseases and many years after acute infantile lung infections. ${ }^{11}$ In addition some normal children without any respiratory symptoms may have hyperresponsive airways. ${ }^{9}$ Our finding of increased airway responsiveness in low birthweight children was not related to their prematurity, as we were unable to show any direct relation between airway responsiveness and gestational age or birth weight. The possibilities that increased bronchial responsiveness resulted from neonatal intensive care or subsequent environmental factors remain to be tested.

Our findings support a familial component in airway responsiveness in both low birthweight children and schoolchildren in general. It is possible that prematurity or neonatal intensive care could in some way enhance the occurrence and persistence of airway responsiveness in low birthweight children. We reject the hypothesis, however, that maternal smooth muscle irritability is a common factor in the aetiology of premature labour in mothers and of bronchial hyper-responsiveness in their children.

We thank the parents and children of our low birthweight cohort for taking part in the study. We also thank the staff, parents, and children of East Acton First School, Berrymede Junior School, and Derwentwater Junior School for their help and cooperation in the research, and the Education Department of the London Borough of Ealing for permission to carry out the study on school premises.

We are grateful to Mrs Barbara Reed for organising the lung function clinics and to Nozhat Choudry for technical help. The cohort was initially enrolled due to the efforts of Dr Pamcla Davies, Dr David Harvey, and Dr David Starte.

The work was supported by the Spastics Socicty, Fisons Pharmaceuticals Ltd, and Glaxo UK Ltd.

\footnotetext{
References

1 Smyth JA, Tabachnik E, Duncan WJ, Reilly BJ, Levison H. Pulmonary function and bronchial hyperreactivity in long-term survivors of bronchopulmonary dysplasia. Pediatrics 1981;68:336-40.

2 Noble-Jamieson CM, Lukeman D, Silverman M, Davies PA. Low birthwcight children at school age: neurological, psychological and pulmonary function. Seminars in Perinatology 1982;6:266-73.

3 Bertrand JM, Riley SP, Popkin J, Coates AL. The long-term
} 
pulmonary sequelae of prematurity. The role of familial airway hyperreactivity and the respiratory distress syndrome. $N$ Engl J Med 1985;312:742-5.

4 Riedel F. Long-term effects of artificial ventilation in neonates. Acta Paediatr Scand 1987;76:24-9.

5 MacLusky IB, Stringer D, Zafen J, Smallhorn J, Levison H. Cardiorespiratory status in long-term survivors of prematurity, with and without hyaline membrane disease. Pediatr Pulmonol 1986;2:94-102.

6 Nickerson BG, Taussig LM. Family history of asthma in infants with bronchopulmonary dysplasia. Pediatrics 1980;65:1140-4.

7 Yan K, Salome C, Woolcock AJ. Rapid method for measurement of bronchial responsiveness. Thorax 1983;38:760-5.

8 Woolcock AJ, Peat JK, Salome CM, et al. Prevalence of bronchial hyperresponsiveness and asthma in a rural adult population. Thorax 1987;42:361-8.
9 Silverman $\mathrm{M}$, Wilson $\mathrm{N}$. Bronchial responsiveness in children: a clinical view. In: Milner AD, Martin J, eds. Paediatric and neonatal respiratory medicine. London: Butterworth, 1985: 161-89.

10 Salome CM, Peat JK, Britton WJ, Woolcock AJ. Bronchial hyperresponsiveness in two populations of Australian school children. I. Relation to respiratory symptoms and diagnosed asthma. Clin Allergy 1987;17:271-81.

1 Cockcroft DW, Killian DN, Mellon JJA, Hargreave FE. Bronchial reactivity to inhaled histamine: a method and clinical survey. Clin Allergy 1977;7:235-43.

Correspondence to Dr M Silverman, Department of Paediatrics, Hammersmith Hospital, London W12 0HG.

Accepted 2 March 1988 